\title{
Computations of Magnetic Forces in Multipole Field Electromagnetic Launcher
}

\author{
Srichandan Kondamudi*, Mallikarjuna Rao Pasumarthi \\ Department of Electrical Engineering \\ Andhra University, Visakhapatnam, India \\ *Corresponding author: srichandank@gmail.com
}

(Received January 21, 2019; Accepted April 2, 2019)

\begin{abstract}
Multipole Field Electromagnetic Launchers (MFEML) is one of the radial electromagnetic launching mechanisms, which can propel a payload for long distances. This paper proposes formulae for inductance based on the magnetic flux distribution in the coils of MFEML. Flux lines flow is sectionalized, for each section reluctance formulae is derived based on the position of the projectile. Based on the principles of the Lorentz equation, magnetic forces are calculated. This paper presents an electrical and magnetic equivalent circuit of MFEML. The velocity and force characteristics are obtained for the proposed formulae. The results are validated using Finite element analysis.
\end{abstract}

Keywords- Electromagnetics, Reluctance, Electrical and magnetic equivalent circuit.

\section{Introduction}

Multipole Field Electromagnetic Launchers (MFEML) has the potential of developing huge thrust force, large driven mass, super velocity launch and steady maglev compared to conventional electrical launchers (Zhu et al., 2010; Zhu et al., 2012; Musolino et al., 2013; Raj et al., 2019). The basic design and analysis of MFEML proposed in the existing literature (Zhu et al., 2010) is suffering with following insufficiency,

(a) catapult coil and acceleration coils are having identical characteristics (Lin and Chen, 2014),

(b) Inductance formulae mentioned is not depending on the position of the projectile (Babic and Akyel, 2000, 2006; Conway, 2007),

(c) The negligible thickness of the current sheet was considered (Musolino et al., 2013) and

(d) Force was calculated by neglecting the leakage fluxes.

Combination of rails is introduced (Xue et al., 2017; Yan et al., 2017) but no specific inductance values were mentioned. Different connection patterns of MFEML was analyzed and experimentally tested a single-stage launcher (Luo et al., 2013), but the analysis was carried out excluding the leakage fluxes. However, previous studies excluded the leakage fluxes and instead created an identical electrical equivalent circuit for both the coils. And no research was carried out on the Magnetic equivalent circuit and section-wise flux-paths of the MFEML.

In this paper, an attempt is made to derive the expression for the inductance of the acceleration coils based on the reluctance principle. The force is calculated with respect to the position of the projectile. The results are tabulated and verified with FEA. A formula was proposed to find the force exerted by the cylindrical spiral catapult coil on the projectile based on the distance between the coil and projectile. A simulation is carried out to calculate the electromagnetic forces at the different 
International Journal of Mathematical, Engineering and Management Sciences

Vol. 4, No. 3, 761-774, 2019

https://dx.doi.org/10.33889/IJMEMS.2019.4.3-059

projectile position. Effect of changing the poles on the force has been examined. The results obtained are compared and validated with FEA.

\section{Force Calculation For Acceleration Coil}

The working principle and the basic characteristics of MFEML are elaborated in (Zhu et al., 2010; Zhu et al., 2012; Musolino et al., 2013). In brief, the catapult coil will give the initial push to the projectile and the acceleration coils will guide the projectile to move along the axis with high thrust. The catapult coil conductor is considered as cylindrical shape and it is kept in spiral arrangement. The acceleration coils and catapult coil are energized from a capacitor bank. For improving the performance, the inner portion of the projectile is filled with non-conducting material (rubber). Figure 1 shows the arrangement of a Single stage Multipole Field Acceleration Coils without and with projectile.
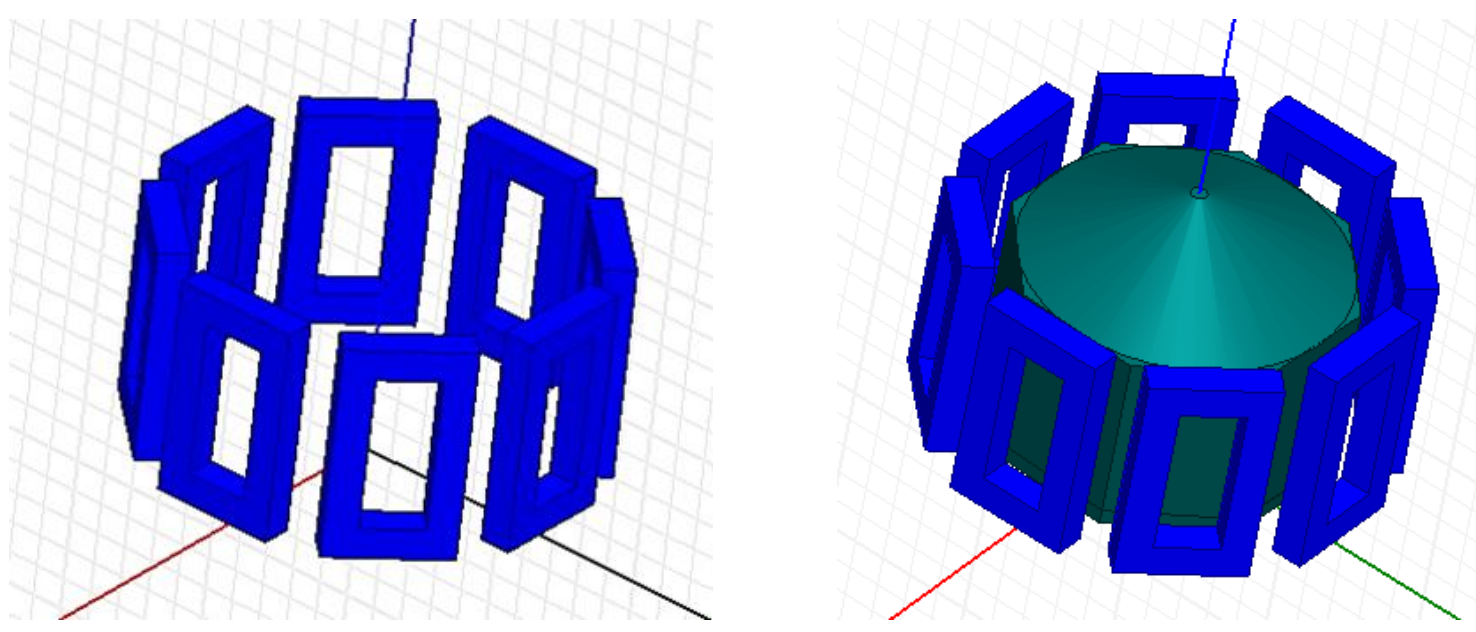

Figure 1. Arrangement of single stage acceleration coils without and with projectile

The Lorentz force generated on the projectile by the acceleration coil is derived from the principle of electro-mechanical energy conversion. The expression is

$F=\frac{1}{2} i^{2} \frac{d L}{d x}$

The expression of electromechanical energy conversion convinces that inductance based on the position of projectile has a remarkable effect on the force. With this statement, the calculation of the inductance will be the key point in defining the characteristics of the launcher. In this section, an expression for the inductance is derived based on the flux distribution method.

For the electromagnetic analysis, a single coil is considered and the flux lines are obtained using FEMM as shown in Figure 2. With reference to the Flux flow diagram, various flux paths are identified. The flux path is assumed to have a flux of $\phi$ in the induction coil. It crosses the air gap, splits evenly in the projectile, and then re-crosses the air gap to the other side of the coil. The reluctances of the induction coil, air gap, and projectile for the flux path are denoted as $R_{c}, R_{g}$ and $R_{\mathrm{p}}$ respectively. 
International Journal of Mathematical, Engineering and Management Sciences

Vol. 4, No. 3, 761-774, 2019

https://dx.doi.org/10.33889/IJMEMS.2019.4.3-059
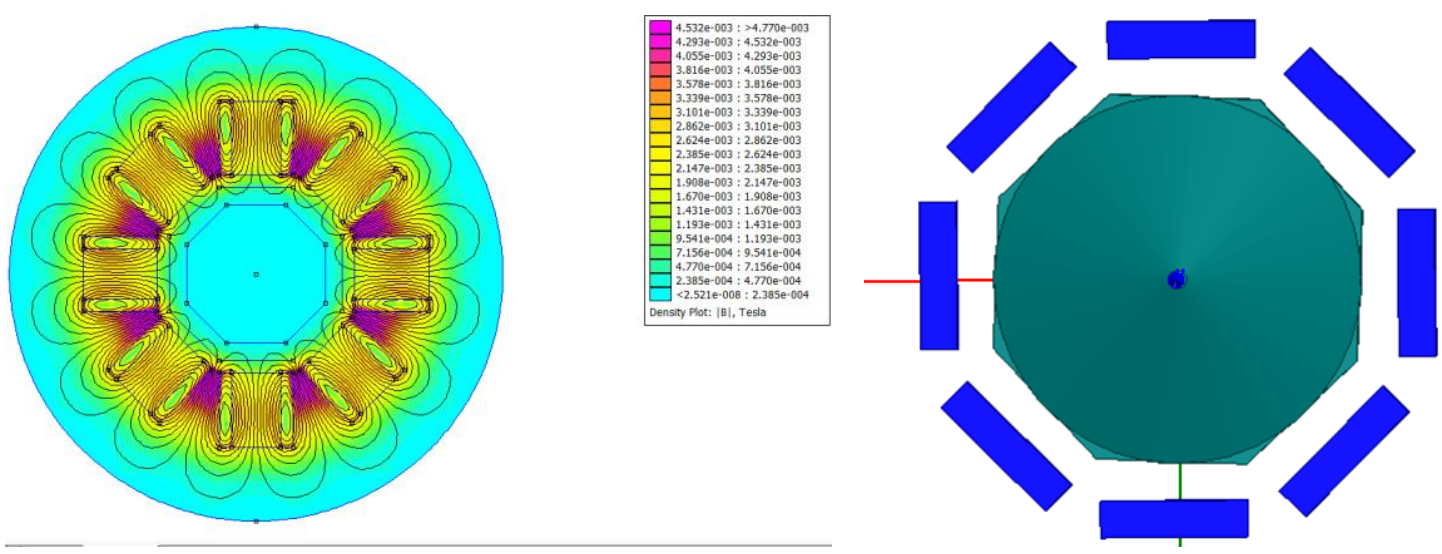

Figure 2. Flux lines flow in MFEML (top view)

The expressions of the reluctance for each flux path (when the projectile is completely inside the coil zone) are derived and presented as

\subsection{Projectile is Completely Inside the Coil Zone}

a) The Reluctance of Flux Path 1

Reluctance in the induction coil

$\mathrm{R}_{1 c 1}=\frac{5 l_{c}}{\mu_{o} \mu_{r} w_{c}\left(h_{c}-t\right)}$

Reluctance in Air-gap

$\mathrm{R}_{1 g 1}=\frac{40 l_{g}}{\mu_{o} w_{p}\left(4 h_{c}+5 l_{p}-9 t\right)}$

Reluctance in Moving Projectile

$\mathrm{R}_{1 p 1}=\frac{\pi}{4 \mu_{o} \mu_{r p} h_{m} w_{p}}\left(\frac{\sqrt{l_{p+}^{2} h_{m}^{2}}}{2 l_{p}}-3 \frac{\sqrt{\left(\frac{3 l_{p}+t}{4}\right)^{2}+\left(\frac{2 h_{m}}{3}\right)^{2}}}{\left(3 l_{p}+t\right)}\right) \times \sqrt{\left(\frac{7 l_{p}+t}{8}\right)^{2}+\left(\frac{5 h_{m}}{6}\right)^{2}}$

Reluctance in the air gap to reach other side of the coil

$\mathrm{R}_{1 \circ g 1}=\frac{4 \pi\left(7 h_{m}+6 l_{g}+12 l_{c}\right)}{3 \mu_{o} w_{p} h_{m}}$

b) The Reluctance of Flux Path 2

Reluctance in the induction coil 
International Journal of Mathematical, Engineering and Management Sciences

Vol. 4, No. 3, 761-774, 2019

https://dx.doi.org/10.33889/IJMEMS.2019.4.3-059

$\mathrm{R}_{1 c 2}=\frac{5 l_{c}}{\mu_{o} \mu_{r} w_{c}\left(h_{c}-t\right)}$

Reluctance in Air-gap

$\mathrm{R}_{1 g 2}=\frac{40 l_{g}}{\mu_{o} w_{p}\left(4 h_{c}+5 l_{p}-9 t\right)}$

Reluctance in Projecting Projectile

$\mathrm{R}_{1 p 2}=\frac{3 \pi}{4 \mu_{o} \mu_{r p} h_{m} w_{p}}\left(\frac{\sqrt{\left(\frac{3 l_{p}+t}{4}\right)^{2}+\left(\frac{2 h_{m}}{3}\right)^{2}}}{\left(3 l_{p}+t\right)}-\frac{\sqrt{\left(\frac{l_{p}+t}{2}\right)^{2}+\left(\frac{h_{m}}{3}\right)^{2}}}{\left(l_{p}+t\right)}\right) \times \sqrt{\left(\frac{5 l_{p}+3 t}{8}\right)^{2}+\left(\frac{h_{m}}{8}\right)^{2}}$

Reluctance in the air gap to reach other side of the coil

$\mathrm{R}_{1 \circ g 2}=\frac{2 \pi\left(h_{m}+3 l_{g}+6 l_{c}\right)}{\mu_{o} w_{p} h_{m}}$

The expressions of the reluctance for each flux path (when the projectile is completely outside the coil zone) are derived and presented as

\subsection{Projectile is Completely Outside the Coil Zone}

a) The Reluctance of Flux Path 1

Reluctance in the induction coil

$\mathrm{R}_{2 c 1}=\frac{5 l_{c}}{\mu_{o} \mu_{r} w_{c}\left(h_{c}-t\right)}$

Reluctance in Air-gap

$\mathrm{R}_{2 g 1}=\frac{\pi}{8 \mu_{o} w_{c}}\left(\frac{\sqrt{\left(h_{c}\right)^{2}+\left(l_{g}+h_{m}\right)^{2}}}{\left(l_{g}+h_{m}\right)\left(h_{c}\right)}-\frac{\sqrt{9\left(4 h_{c}+t\right)^{2}+25\left(3 l_{g}+2 h_{m}\right)^{2}}}{\left(2 h_{m}+3 l_{g}\right)\left(4 h_{c}+t\right)}\right) \times \sqrt{\left(\frac{9 h_{c}+t}{10}\right)^{2}+\left(\frac{5 h_{m}}{6}+l_{g}\right)^{2}}$

Reluctance in Moving Projectile

$\mathrm{R}_{2 p 1}=\frac{\pi \sqrt{\left(2 l_{p}\right)^{2}+\left(\frac{15 h_{m}}{18}\right)^{2}}}{2 \sqrt{2} \mu_{o} \mu_{r}\left(w_{p} h_{m}-\frac{8 \sqrt{2} h_{m} l_{p} w_{p}}{\sqrt{\left(6 l_{p}\right)^{2}+\left(2 h_{m}\right)^{2}}}\right)}$

Reluctance in air gap to reach other side of the coil

$\mathrm{R}_{2 o g 1}=\frac{\left(l_{c}+l_{g}\right)}{\mu_{o} w_{p} l_{p}}$ 
International Journal of Mathematical, Engineering and Management Sciences

Vol. 4, No. 3, 761-774, 2019

https://dx.doi.org/10.33889/IJMEMS.2019.4.3-059

\section{b) The Reluctance of Flux Path 2}

Reluctance in the induction coil

$\mathrm{R}_{2 c 2}=\frac{5 l_{c}}{2 \mu_{o} \mu_{r} w_{c}\left(h_{c}-t\right)}$

Reluctance in Air-gap

$\mathrm{R}_{2 g 2}=\frac{\pi}{8 \mu_{o} w_{c}}\left(\frac{\sqrt{\left(3\left(4 h_{c}+t\right)\right)^{2}+\left(5\left(3 l_{g}+2 h_{m}\right)\right)^{2}}}{\left(4 h_{c}+t\right)\left(3 l_{g}+2 h_{m}\right)}-\frac{\sqrt{\left(\left(2 h_{c}+t\right)\right)^{2}+\left(5\left(l_{g}\right)\right)^{2}}}{\left(2 h_{c}+3 t\right) l_{g}} \times \sqrt{\left(\frac{\left.6 l_{g}+2 h_{m}\right)^{2}}{6}+\left(\frac{\left.3 h_{c}+2 t\right)^{2}}{5}\right.\right.}\right.$

Reluctance in Moving Projectile

$\mathrm{R}_{2 p 2}=\frac{\pi}{32 \mu_{o} \mu_{r p} l_{p} h_{m} w_{c}}\left(\sqrt{\left(6 l_{p}\right)^{2}+\left(2 h_{m}\right)^{2}} \times \sqrt{\left(2 l_{p}\right)^{2}+\left(\frac{2 h_{m}}{3}\right)^{2}}\right.$

Reluctance in the air gap to reach other side of the coil

$\mathrm{R}_{2 o g 2}=\frac{\left(l_{c}+l_{g}\right)}{\mu_{o} l_{p} w_{p}}$

where

$1_{c}$ is the length of the coil in meters

$l_{\mathrm{g}}$ is the length of the air gap in meters

$\mathrm{h}_{\mathrm{c}}$ is the height of the coil in meters

$l_{p}$ is the length of the projecting projectile in meters

$\mathrm{h}_{\mathrm{p}}$ is the height of the projecting projectile in meters

$\mathrm{h}_{\mathrm{m}}$ is the height of the metallic sheath in projecting projectile in meters

$\mathrm{W}_{\mathrm{c}}$ is the width of the coil in meters

$\mathrm{W}_{\mathrm{p}}$ is the width of the coil in meters

$t$ is the thickness of the coil winding in meters

$\mu_{0}$ is permeability of the air

$\mu_{\mathrm{rp}}$ is relative permeability of the projecting projectile

$\mathrm{n}$ is a number of turns.

In a similar way, ' $n$ ' flux paths are considered and the respective reluctances expressions are derived. Figure 3 shows the overall magnetic circuit of MFEML for single acceleration coil. 
International Journal of Mathematical, Engineering and Management Sciences

Vol. 4, No. 3, 761-774, 2019

https://dx.doi.org/10.33889/IJMEMS.2019.4.3-059

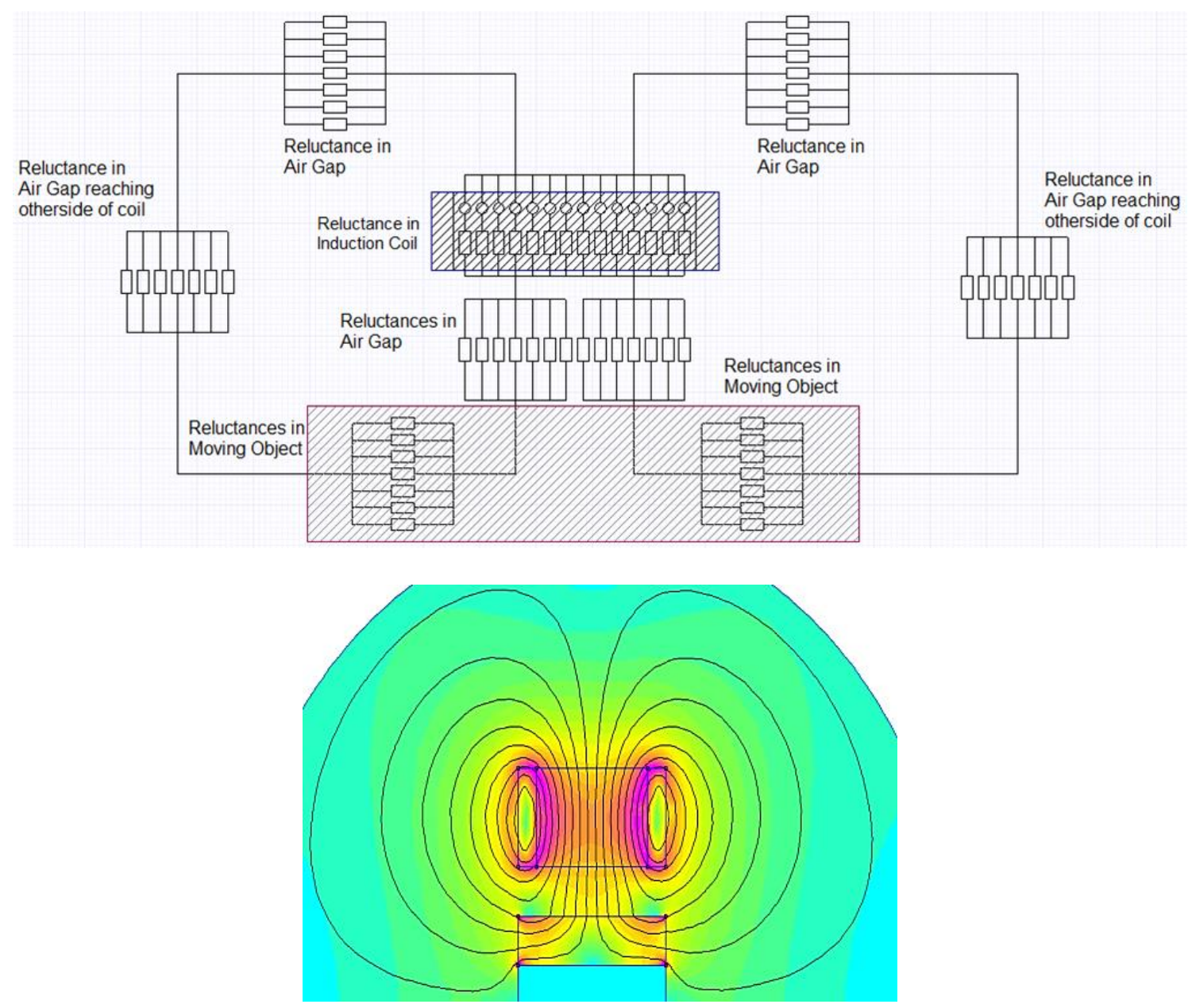

Figure 3. Magnetic circuit of MFEML for single coil (right side view) and different flux lines from coil

Using the basic principles of reluctance combinations the final equivalent magnetic circuit is developed as shown in Figure 4.

The complete inductance offered by the induction coil based on the position of the projectile is found using

$L(x)=\frac{N^{2}}{R_{\text {total }}(x)}$

where $x$ is the position of the projectile.

$\mathrm{R}_{\text {total }}(x)=2 R_{e q(\text { coil })}+2 R_{\text {eq(airgap })}+\frac{2 R_{\text {eq(airgap })}+R_{\text {eq(object })}}{2}$. 
International Journal of Mathematical, Engineering and Management Sciences

Vol. 4, No. 3, 761-774, 2019

https://dx.doi.org/10.33889/IJMEMS.2019.4.3-059

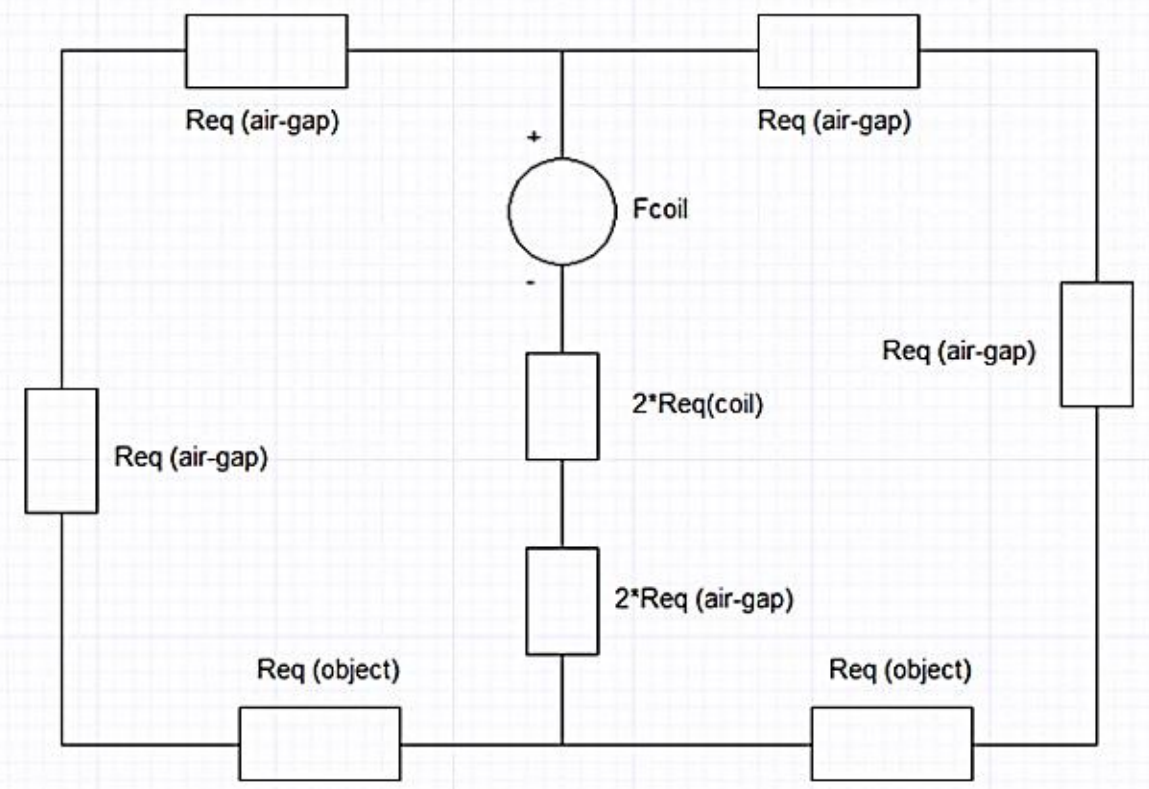

Figure 4. Magnetic Equivalent Circuit of MFEML for single coil

\section{Force Calculation For Spiral Catapult Coil}

The induction coils cannot provide the initial thrust because the force generated by the induction coil is three dimensional (Yan et al., 2017). Due to which the projectile cannot move smoothly in the axis of the barrel. To overcome this problem, the catapult coil is used in the MPEML, which provide the initial thrust such that the projectile is given the direction in which way it has to propel. In this section, the inductance offered by the catapult coil is presented. The catapult coil considered in this work is a cylindrical cooper wire in a spiral arrangement which is excited by a capacitor bank. The arrangement of spiral catapult coil is shown in Figure 5.
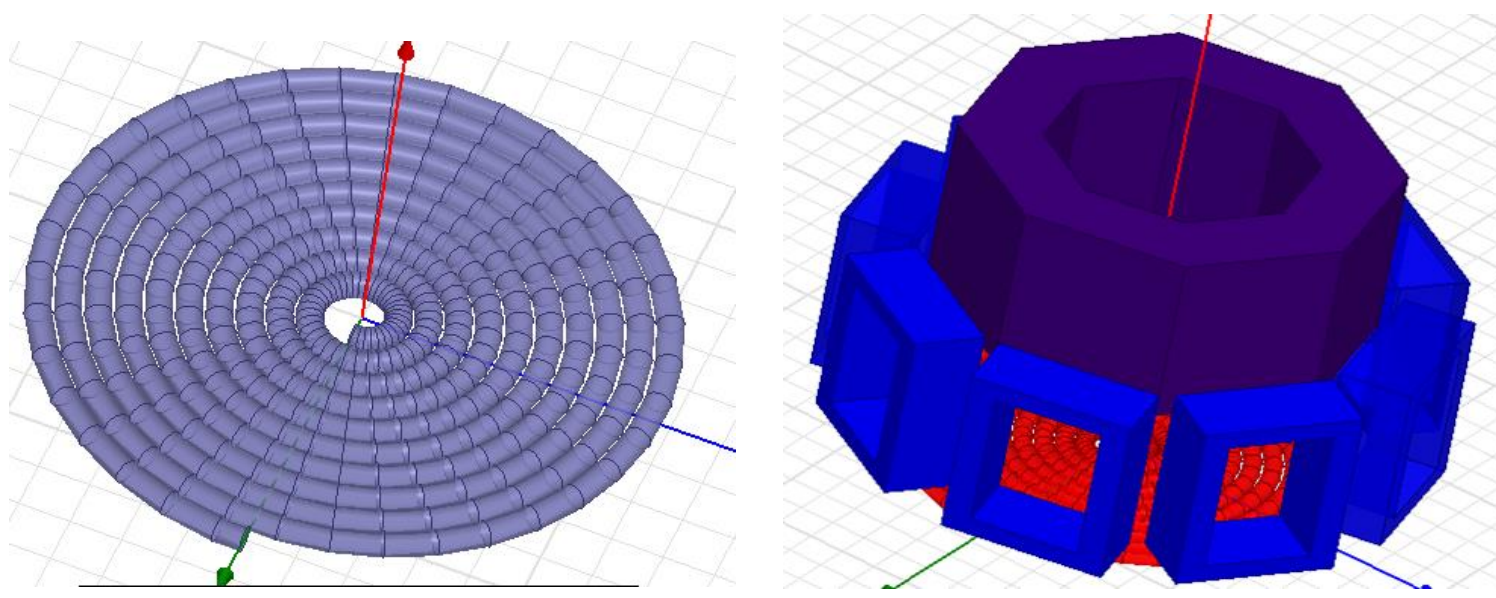

Figure 5. Arrangement of spiral catapult coil and MFEML with sprial catapult coil 
International Journal of Mathematical, Engineering and Management Sciences

Vol. 4, No. 3, 761-774, 2019

https://dx.doi.org/10.33889/IJMEMS.2019.4.3-059

The force between the projectile and the coil is based on the skin-depth the projectile is given as (Frederick, 2009; Lin and Chen, 2014)

$F_{z}=\frac{\mu_{0} i^{2} z k^{\prime}}{2 r^{2}\left(1-\left(1-k^{\prime}\right)^{2}\right)}\left[\left(\left(1-k^{\prime}\right)^{2}\right) * k\left(k^{\prime}\right)\right)-\left(1-0.5\left(k^{\prime}\right)^{2} * \int_{0}^{\frac{\pi}{2}}\left(1-\sin ^{2} \theta\right)^{2}\right]$

where

$k^{\prime}=\sqrt{\frac{4 r^{2}}{(2 * r)^{2}+z^{2}}}$

$\mathrm{r}=$ the inner radius of the coil in $\mathrm{mm}$

$\mathrm{i}=$ current in the coil in amperes

$\theta=$ sweep angle

$\mathrm{Z}=$ distance between the coil and the projectile.

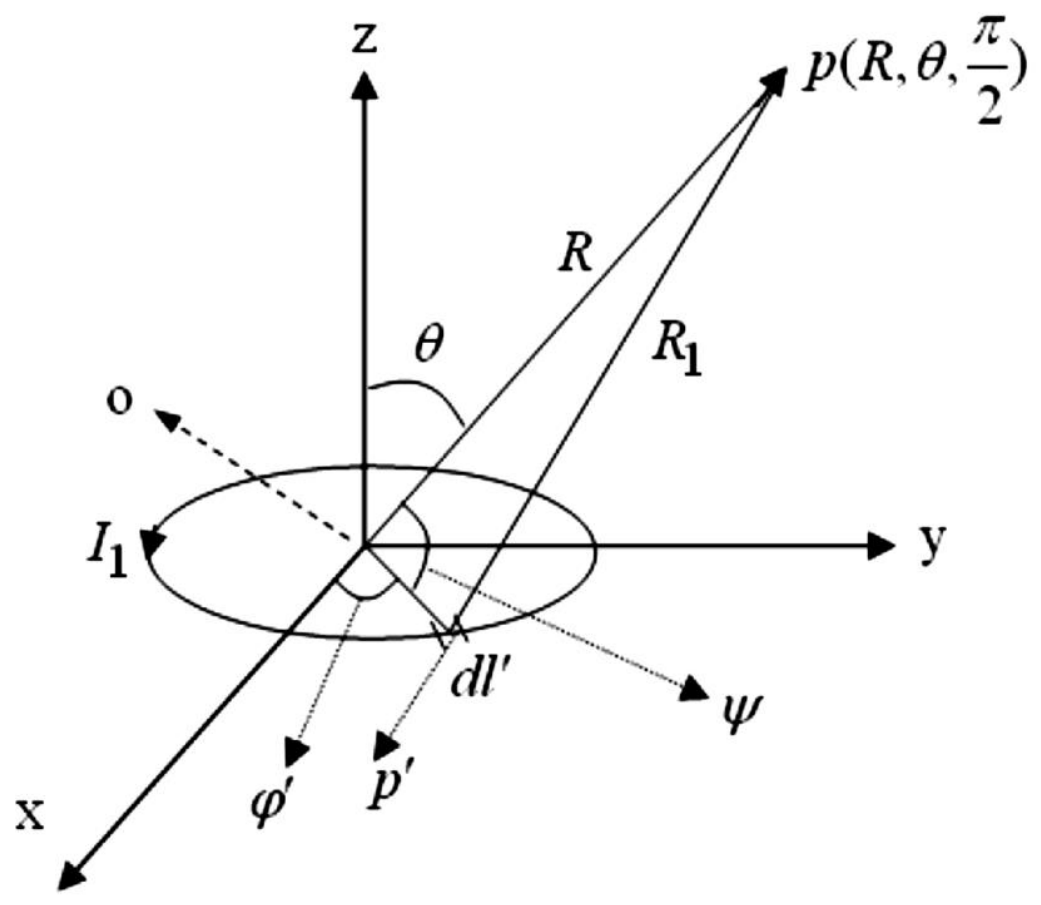

Figure 6. Determination of vector potential of a current carrying ring in any given point $\mathrm{P}$

The parameters used in Equation (19) are explained using Figure 6. Sweep angle is the angle between the z-plane of the spiral coil with $\mathrm{R}$ (where $\mathrm{R}$ is the distance between the origin and the field point P). Su et al. (2009) are referred to derive the formulae for the force. From the above analysis, it is identified that the catapult coil and acceleration coils are having contrasting characteristics. 
International Journal of Mathematical, Engineering and Management Sciences

Vol. 4, No. 3, 761-774, 2019

https://dx.doi.org/10.33889/IJMEMS.2019.4.3-059

\section{Electrical Equivalent Circuit For MFEML}

An electrical equivalent circuit refers to a theoretical circuit that retains all of the electrical characteristics of a given circuit. Often, an equivalent circuit is sought that simplifies the calculation, and more broadly, that is the simplest form of a more complex circuit in order to aid analysis. The electrical equivalent circuit of MFEML is shown in Figure 7. The inductance parameters of the electrical equivalent are calculated from the expression derived in section 2.

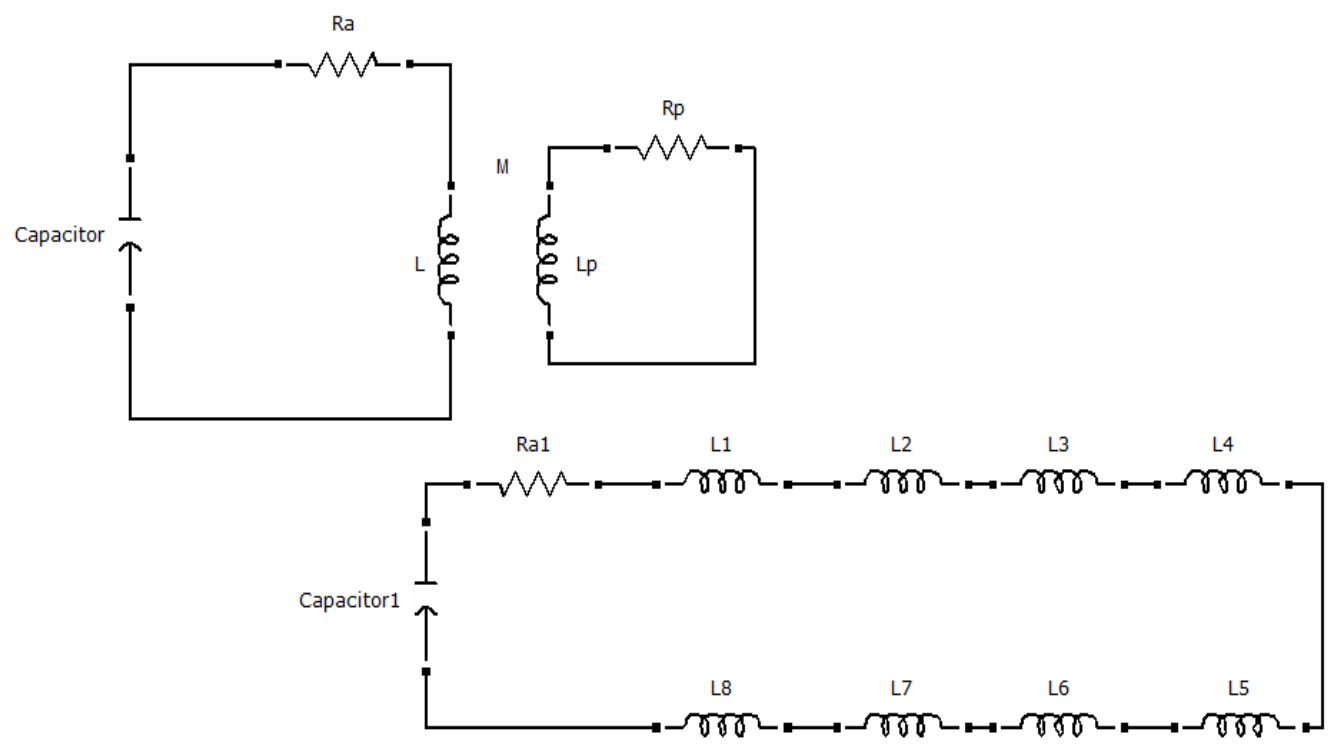

Figure 7. Electrical Equivalent circuit of MFEML

The resistance of the acceleration coil is calculated using

$R_{c}=\frac{\rho l_{w}}{A_{w}}$

where

$\mathrm{L}_{\mathrm{w}}=$ length of the wire

$\mathrm{A}_{\mathrm{w}}=$ Area of the wire.

The inductance of the catapult coil is expressed as

$L_{c}=\frac{N^{2} A^{2}}{30 A-11 D_{i}}$

$A=D_{i}+N_{c} \frac{(w+s)}{2}$

where 
International Journal of Mathematical, Engineering and Management Sciences

Vol. 4, No. 3, 761-774, 2019

https://dx.doi.org/10.33889/IJMEMS.2019.4.3-059

$A=$ Area of the Spiral Coil

$\mathrm{D}_{\mathrm{i}}=$ Inner Diameter of catapult coil

$\mathrm{s}=$ Distance between the coil winding

$\mathrm{W}=$ Wire diameter of catapult coil

$\mathrm{N}_{\mathrm{c}}=$ Number of turns catapult coil

$\mathrm{D}_{\mathrm{o}}=$ Outer Diameter catapult coil

\section{Results}

The single stage model of a Multipole Electromagnetic Launcher is simulated to analyze its performance. The specifications mentioned in (Zhu et al., 2010) are considered to simulate the acceleration coil and catapult coil models represented in Table 1.

Table 1. System parameters

\begin{tabular}{|l|l|}
\hline \multicolumn{2}{|c|}{ Induction Acceleration Coil } \\
\hline Number of Coils & 8 \\
\hline Material & Copper \\
\hline Section & Rectangular \\
\hline Inner Rectangle & $18 \mathrm{~mm} * 18 \mathrm{~mm}$ \\
\hline Outer Rectangle & $28.5 \mathrm{~mm} * 28.5 \mathrm{~mm}$ \\
\hline Length & $10.55 \mathrm{~mm}$ \\
\hline Number of Turns & 50 \\
\hline Catapult Coil & \\
\hline Material & Copper \\
\hline Section & Cylindrical \\
\hline Dimensions & $2 \mathrm{~mm} * 16 \mathrm{~mm}$ \\
\hline Layers of pancake winding & 15 \\
\hline Number of Turns & 30 \\
\hline Projectile & \\
\hline Material & Pure Iron \\
\hline Mass & $0.2 \mathrm{~kg}$ \\
\hline Section & Octagon \\
\hline Inner Radius & $29 \mathrm{~mm}$ \\
\hline Outer Radius & $37 \mathrm{~mm}$ \\
\hline Length & $30 \mathrm{~mm}$ \\
\hline The permeability of the Pure Iron & 5000 \\
\hline The permeability of the Air & $4 * \mathrm{pi}^{*} 10^{\wedge}-7 \mathrm{H} / \mathrm{m}$ \\
\hline Conductivity of Copper & $5.96 \times 10^{7} \mathrm{~s} / \mathrm{m}$ \\
\hline
\end{tabular}

The inductance profile of a single induction coil in MFEML is shown in Figure 8. It is observed that the maximum and minimum inductance of the induction coil when the projecting projectile is completely inside is $0.23304 \mathrm{mH}$ and $0.024107 \mathrm{mH}$ respectively. From the finite element analysis, the maximum inductance value attained is $0.2419 \mathrm{mH}$ and the minimum inductance value observed is $0.02401 \mathrm{mH}$. Hence the values are verified using Finite Element Analysis. 
International Journal of Mathematical, Engineering and Management Sciences

Vol. 4, No. 3, 761-774, 2019

https://dx.doi.org/10.33889/IJMEMS.2019.4.3-059

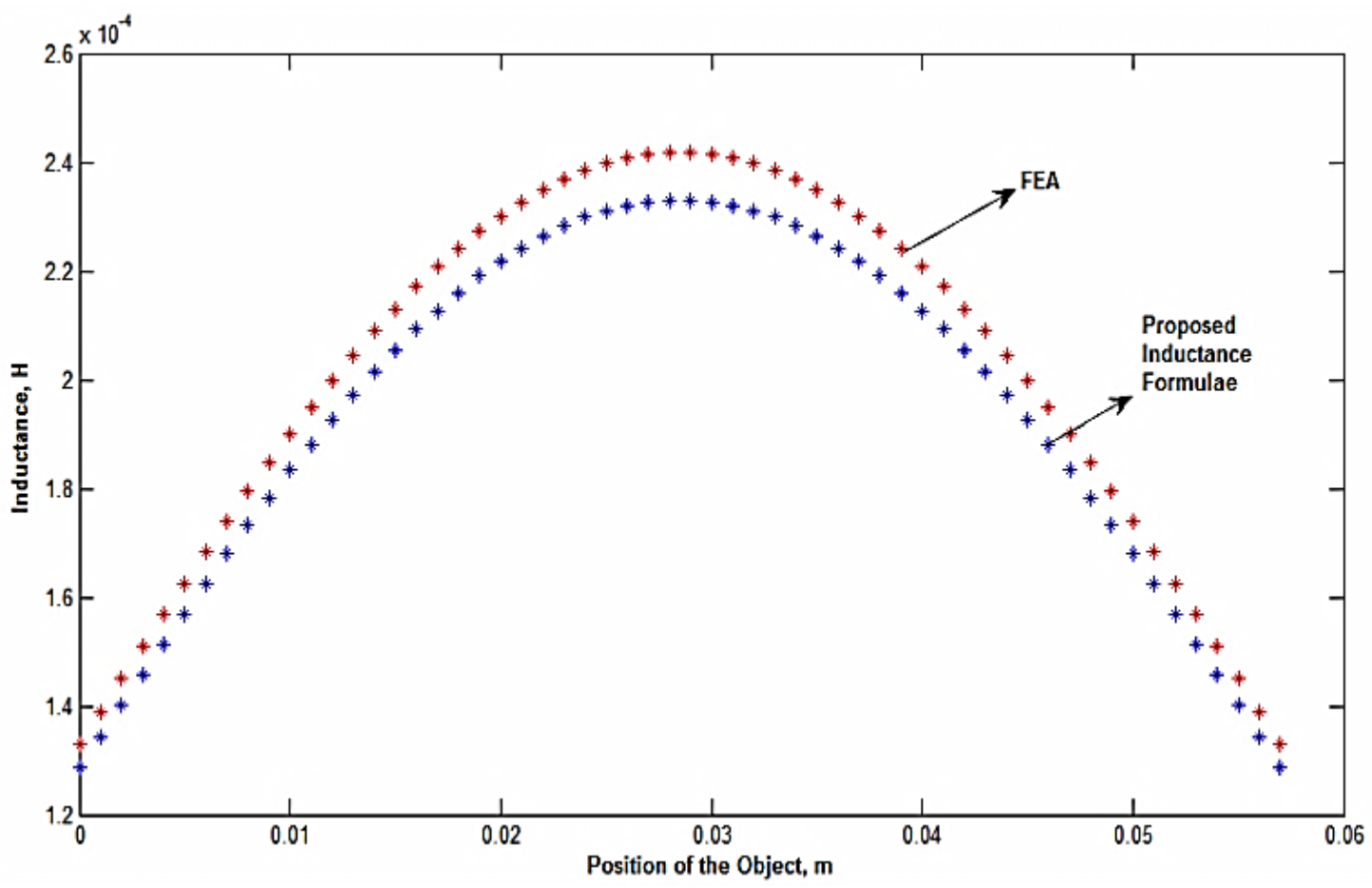

Figure 8. Inductance profile of a single coil of MFEML

A capacitor of $200 \mu \mathrm{F}$ is initially charged to a voltage of $40 \mathrm{kV}$ for catapult switching, and a capacitor of $400 \mu \mathrm{F}$ charged with $50 \mathrm{kV}$ for accelerating coil switching (Zhu et al., 2010). The circuit switches are triggered by the sensor detecting the projectile position. Rushdi et al. (2019) is referred for different switching sequence.

Figure 9 shows the characteristics of velocity, force, and current in the acceleration coils respectively. From the characteristics, it is observed that the initial velocity of $0.05 \mathrm{~m} / \mathrm{sec}$ is generated by catapult coil and the acceleration coil is pulling the projectile and enhanced the velocity to $0.55 \mathrm{~m} / \mathrm{sec}$. The force exerted at starting to overcome the initial friction by catapult coil is $60 \mathrm{kN}$ and the acceleration coil has provided the remaining force $(100 \mathrm{kN})$ to accelerate the projectile. The nature of curves approximately matches with (Zhu et al., 2010). The comparison of results mentioned in Table 2 shows that the values are a bit far, as the limitations stated in section I are considered. 
International Journal of Mathematical, Engineering and Management Sciences

Vol. 4, No. 3, 761-774, 2019

https://dx.doi.org/10.33889/IJMEMS.2019.4.3-059

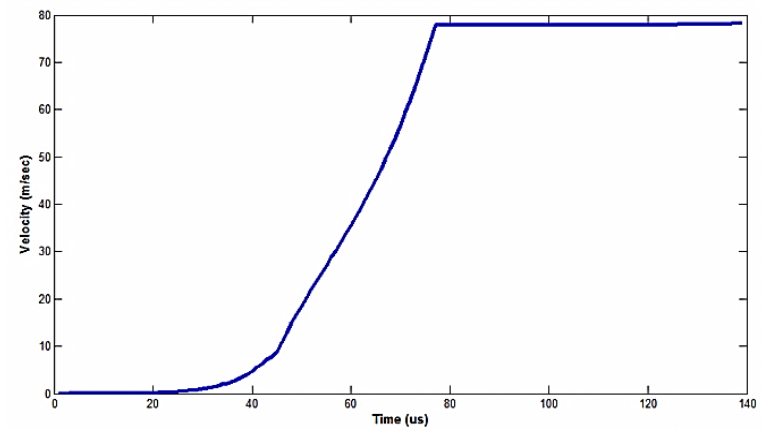

(a)

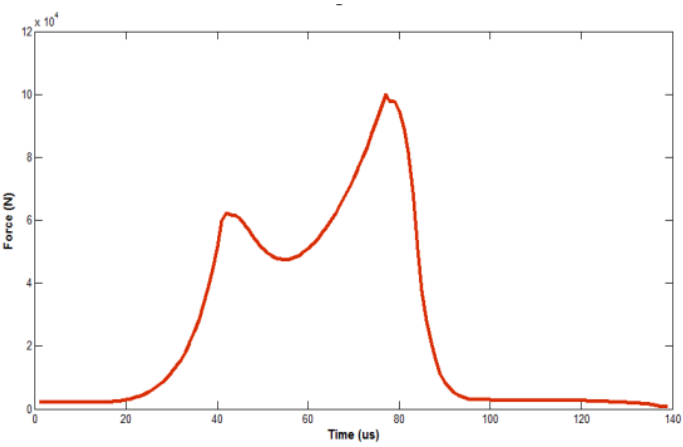

(b)

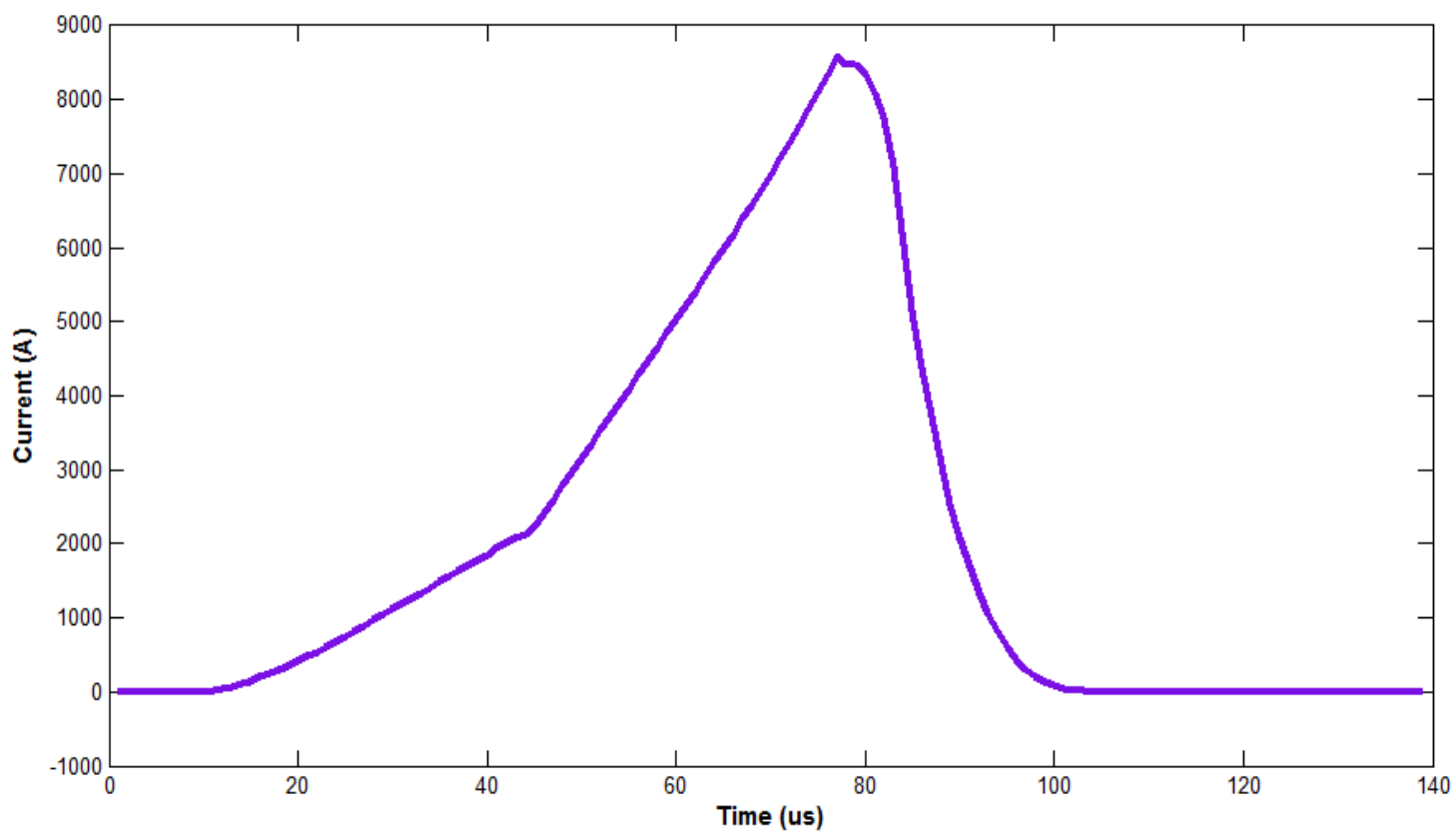

(c)

Figure 9. Performance characteristics of MFEML (a) Velocity, (b) Force and (c) Current

Table 2. Comparison of results with the existing method (Octapole system)

\begin{tabular}{|c|c|c|}
\hline & Zhu et al. (2010) & Proposed Method \\
\hline Force & $266 \mathrm{kN}$ & $100 \mathrm{kN}$ \\
\hline Muzzle Velocity & $232.47 \mathrm{~m} / \mathrm{sec}$ & $78.19 \mathrm{~m} / \mathrm{sec}$ \\
\hline
\end{tabular}

The scope of the paper is extended by considering numbers of poles in the MFEML. In Table 3, the performance of the system is compared by considering different number of accelerating poles. With reference to Table 3, the values of velocity and force will enhance when number of poles in the system increase. 
International Journal of Mathematical, Engineering and Management Sciences

Vol. 4, No. 3, 761-774, 2019

https://dx.doi.org/10.33889/IJMEMS.2019.4.3-059

With reference to the force and velocity values, MFEML has capability to replace the chemical launchers, hydraulic launchers, linear induction motor based launchers and electromagnetic based actuation systems.

Table 3. Comparison of performance of system for different number of accelerating poles

\begin{tabular}{|c|c|c|c|}
\hline & Hexapole & Octapole & Decapole \\
\hline Force & $88 \mathrm{kN}$ & $100 \mathrm{kN}$ & $114 \mathrm{kN}$ \\
\hline Muzzle Velocity & $61 \mathrm{~m} / \mathrm{sec}$ & $78.19 \mathrm{~m} / \mathrm{sec}$ & $84.22 \mathrm{~m} / \mathrm{sec}$ \\
\hline
\end{tabular}

\section{Conclusions}

This paper elaborates the function and characteristics of Multipole Field Electromagnetic Launcher (MFEML) with the help of Magnetic and Electrical equivalent circuits. An expression for inductance was derived considering sectionalized flux-paths (considering all flux leakages). Using the derived inductance, the resultant force is calculated and verified using Finite Element Analysis. The individual analysis was done for both catapult coil and the acceleration coil. The performance of the system was studied at different number of accelerating poles. Based on the results, it is concluded that the inductance of the coil will depend on the position, leakage fluxes and thickness of the current sheet. The inductance formula proposed here can easily be applicable for coils of any random size and shape. Moreover, the proposed methodology considers all the parameters and design aspects as real as possible. Hence it can be stated that the proposed design for MFEML happens to generate realistic design sheet.

\section{Conflict of Interest}

The authors confirm that there is no conflict of interest to declare for this publication.

\section{Acknowledgement}

The authors would like to express their sincere thanks to the referee and for their valuable suggestions towards the improvement of the paper.

\section{References}

Babic, S. I., \& Akyel, C. (2006). New analytic-numerical solutions for the mutual inductance of two coaxial circular coils with rectangular cross section in air. IEEE Transactions on Magnetics, 42(6), 1661-1669.

Babic, S., \& Akyel, C. (2000). Improvement in calculation of the self and mutual inductance of thin -wall solenoids and disk coils. IEEE Transactions on Magnetics, 36(4), 1970 - 1975.

Conway, J.T. (2007). Inductance calculations for noncoaxial coils using bessel functions. IEEE Transactions on Magnetics, 43(3), 1023-1034.

Frederick, W.G. (2009). Formulas for the calculation of the magnetic force between coils. Inductance Calculation (pp.205-222). Dover Publication.

Lin, D., \& Chen, X. (2014). Mathematical models of 3D magnetic field and 3D positioning system by magnetic field. Applied Mathematics \& Information Sciences, 8(4), 1647-1654. 
International Journal of Mathematical, Engineering and Management Sciences

Vol. 4, No. 3, 761-774, 2019

https://dx.doi.org/10.33889/IJMEMS.2019.4.3-059

Luo, W., Wang, Y., Gui, Z., Yan, Z., \& Chen, W. (2013). Connection pattern research and experimental realization of single stage multipole field- electromagnetic launcher. IEEE Transactions on Plasma Science, 41(11), 3173 - 3179.

Musolino, A., Rizzo, R., \& Tripodi, E. (2013). Travelling wave multipole field electromagnetic launcher: an SOVP analytical model. IEEE Transactions on Plasma Science, 41(5), 1201-1208.

Raj, P.G., Esakki, B., \& Ganesan, S. (2019). Evaluation of mechanical strength characteristics of double ducted unmanned amphibious aerial vehicle using finite element analysis. International Journal of Mathematical, Engineering and Management Sciences, 4(2), 420-431.

Rushdi, A.M.A. (2019). Utilization of symmetric switching functions in the symbolic reliability analysis of multi-state k-out-of-n systems. International Journal of Mathematical, Engineering and Management Science, 4(2), 306-326.

Su, Y.P., Liu, X., \& Hui, S.Y.R. (2009). Mutual inductance calculation of movable planar coils on parallel surfaces. IEEE Transactions on Power Electronics, 24(4), 1115 - 1123.

Xue, X., Shu, T., Yang, Z., \& Feng, G. (2017). A new electromagnetic launcher by sextupole rails: electromagnetic propulsion and shielding numerical validation. IEEE Transactions on Plasma Science, 45(9), 2541- 2545.

Yan, Z., Long, X., Lu, F., Wang, Y., \& Liu, H. (2017). Study of single-stage double-armature multipole field electromagnetic launcher. IEEE Transactions on Plasma Science, 45(8), 2381 - 2386.

Zhu, Y., Wang, Y., Yan, Z., Dong, L., Xie, X., \& Li, H. (2010). Multipole field electromagnetic launcher. IEEE Transactions on Magnetics, 46(7), 2622- 2627.

Zhu, Y., Wang, Y., Chen, W., Yan, Z., \& Li, H. (2012). Analysis and evaluation of three-stage twisty octapole field electromagnetic launcher. IEEE Transactions on Plasma Science, 40(5), 1399 - 1406. 